TAO, Vol. 16, No. 1, 155-176, March 2005

\title{
Study of Interrelation among Various Surface Layer Parameters during Pre-monsoon and Monsoon Phases over Jodhpur $\left(26^{\circ} 18^{\prime} \mathrm{N}, 73^{\circ} 04^{\prime} \mathrm{E}\right)$, India
}

\author{
N. Das ${ }^{1}$, S. De ${ }^{1}$, J. Chattopadhyay ${ }^{1}$ and U. K. De $e^{1, *}$ \\ (Manuscript received 31 March 2004, in final form 4 November 2004)
}

\begin{abstract}
During the monsoon period of the year 1990, a micrometeorological tower of $30 \mathrm{~m}$ in height was erected at Jodhpur, India, as a part of the multi-institutional field experiment MONTBLEX'90. Various sensors were mounted in the tower to capture different meteorological phenomenon as accurately as possible. The objective of the present work is to study the response of these sensors and then derive different surface layer parameters from it, together with the statistical interrelation between these parameters. Simultaneously, specific weather conditions during a selective period of study have been considered to observe the change in the performance of the instruments. Also how this change affects the surface layer parameters with the presence of a typical weather system has been examined. Finally the analysis shows that the surface layer parameters have good interrelation during deep convective situations.
\end{abstract}

(Key words: Frictional velocity, Frictional temperature, Turbulent kinetic energy, Monin-Obukov length)

\section{INTRODUCTION}

It is recorded that $25 \%$ of India's gross domestic product and $60 \%$ of its workforce are agriculture based. Agriculture in India is still largely dependent on monsoon rain. So it plays a very important role in controlling socio-economic conditions in the country. As a result, study of different surface layer parameters during the onset and active phase of India's summer monsoon is of great interest to both micro and meso-scale meteorologists of this country.

Previously, Rao (1997) estimated the surface temperature over the monsoon trough region.

\footnotetext{
${ }^{1}$ Environmental Science Research Programme, Faculty of Science Jadavpur University, Kolkata

* Corresponding author address: Prof. U. K. De, Environmental Science Research Program, Faculty of Science, Jadavpur University, Kolkata-700032 E-mail: deutpal@hotmail.com
} 
Then attempts were made to gather information about the depth and the nature of the turbulence structure of the turbulent atmospheric boundary layer (Rajkumar et al. 1997). At the same time, mixing ratio, Richardson number, inversion height etc. were studied to get the height of the nocturnal boundary layer (Roy and De 1997). Also a group of scientists worked on the measurement of roughness length, and drag coefficient at different sectors of the monsoon trough (Rao 1997; Mohanty et al. 1997). Surface heat fluxes were also observed by a number of scientists separately for different regions as well as for different periods (Rao et al. 1997; Sadani and Murthy 1997). Moreover, various surface layer parameters and fluxes of sensible heat and momentum have been studied by Viswanadham and Satyanarayana (Viswanadham and Satyanarayana 1997). But all these studies do not include the impact of surrounding weather situations, which may control the surface layer characteristics. Also they did not examine the interrelation between different surface layer parameters and surface heat fluxes.

So, in the present study, at first, various surface boundary layer (i.e., SBL) parameters and surface heat fluxes have been evaluated in a typical dry convective zone of the monsoon trough. The objective is to estimate and study variation of different surface layer parameters like, sensible surface heat flux, turbulent kinetic energy, Monin-Obukhov length, frictional velocity, frictional temperature etc. The interrelation among different SBL parameters is also studied. Simultaneously, interrelation of different surface layer parameters with the surrounding weather condition is studied and attempts have been made to search for interconnections if any exist.

\section{STUDY AREA AND PERIOD OF STUDY}

To investigate the atmospheric boundary layer dynamics over a dry convective region near the western end of the monsoon trough, a $30 \mathrm{~m}$ high instrumented tower was set up in the plain grounds of the Central Arid Zone Research Institute (CAZRI), Jodhpur $\left(26^{\circ} 18^{\prime} \mathrm{N}\right.$, $73^{\circ} 04^{\prime} \mathrm{E}$ ), India, as a part of the multi-institutional, Department of Science and Technology, Government of India coordinated research program called "MONsoon Trough Boundary Layer EXperiment" abbreviated as MONTBLEX (Goel and Srivastava 1989). Jodhpur is in the dry zone at the fringe area of the Thar desert, on the Aravalli range, and has a hill and valley terrain. The study area is shown in Fig. 1. Actually, Jodhpur represents the western Rajasthan, which is relatively bare of vegetation compared with other parts of India (Sikka and Narasimha 1997). The Jodhpur tower over-looked a large $400 \mathrm{~m}$ swath of desert flats (Kailas and Goel 1997). Around the tower, there was fairly good open space with a few small plants of less than $0.5 \mathrm{~m}$ in height grown for research purposes towards the west and north-west. A few, small bush trees of $1 \mathrm{~m}$ to $2 \mathrm{~m}$ height, present close to the tower during the installation, were cut before the experiment started. A $6 \mathrm{~m}$ high building was located at about $100 \mathrm{~m}$ from the tower towards the west and the data acquisition computer was placed inside this building (Rudra Kumar et al. 1997). Rainfall at Jodhpur is normally very low. The area is characterized by dry convection with shallow clouds (Kailas and Goel 1997). During summer monsoon months, the days are extremely hot and followed by sudden nocturnal cooling. The south-west monsoon of the year 1990 over Jodhpur was almost normal with large amounts of rainfall and 


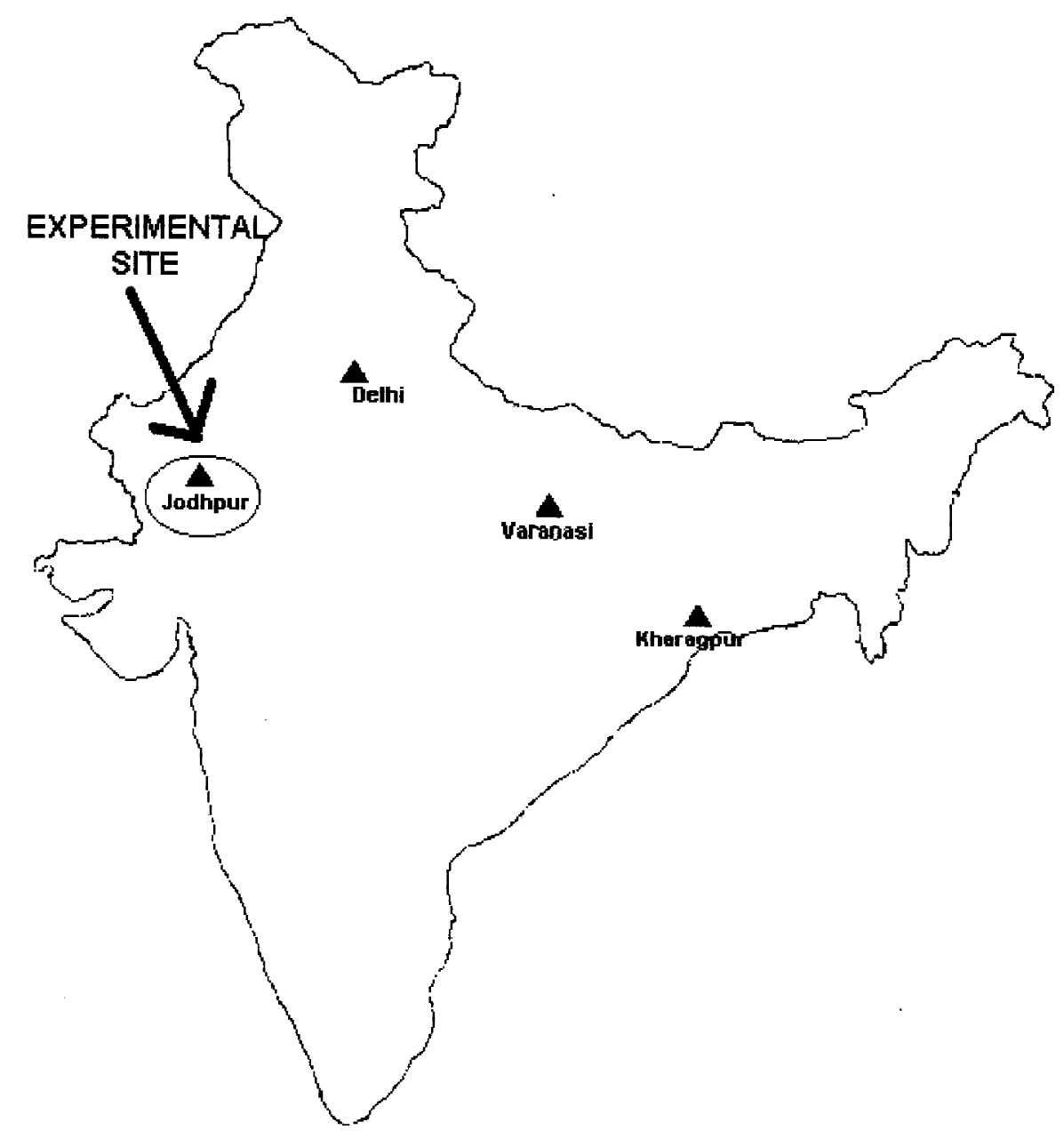

Fig. 1. Study Area.

without any break phase (Srivastav 1997).

During MONTBLEX '90, a 30 m high micrometeorological tower was erected at Jodhpur with six levels of instrumentation. The booms were placed at $1 \mathrm{~m}, 2 \mathrm{~m}, 4 \mathrm{~m}, 8 \mathrm{~m}, 15 \mathrm{~m}$ and $30 \mathrm{~m}$ heights. These are alternatively called $1^{\text {st }}, 2^{\text {nd }}, 3^{\text {rd }}, 4^{\text {th }}, 5^{\text {th }}$ and $6^{\text {th }}$ level respectively. Both fast as well as slow response sensors were placed at various levels of the tower and the details about the instrumentation already exist in the literature (Rudra Kumar and Prabhu 1991). Though both the fast response and slow response sensors are present in the tower, but in the present work only the fast response sensor collected data are utilized. This is mainly because the fast response sensors are more reliable (Rudra Kumar et al. 1995) and their frequency is much higher than the slow response sensors. So it is expected that the fast response sensor can 
capture more efficiently any transient changes in the surface layer.

The period selected for analysis is from 24 June to 29 June and from 17 July to 20 July. Thus a total of ten days' data from two discrete periods has been used for the present study. The first part of the study period falls in the pre-monsoon period for Jodhpur and the other part represents the monsoon period over the same place. This particular period is chosen, as fast response sensor data is available to the authors for that specific period only. Here two types of fast response sensors are present, namely Sonic at the $3^{\text {rd }}$ level and Gill at the $5^{\text {th }}$ level. Sonic measures the $\mathrm{u}, \mathrm{v}, \mathrm{w}$ components of wind speed and temperature, whereas Gill measures only the $\mathrm{u}, \mathrm{v}, \mathrm{w}$ components of wind speed and temperature coming from a separate instrument placed at the $5^{\text {th }}$ level. These two instruments and their quality analysis using profile plots, and energy spectrum etc. have been described in detail in the literature (Rudra Kumar et al. 1997). With the help of the temperature and wind data from the fast response sensors, the following parameters are estimated for the aforementioned 10 days:

(i) Surface parameters like frictional velocity $\mathrm{u}_{*}$, frictional temperature $\theta_{*}$ and sensible heat flux $\mathrm{H}$ are evaluated at the two levels (i.e., for the $3^{\text {rd }}$ and $5^{\text {th }}$ levels) using the eddy correlation method (Kaimal and Finnigan 1994). Correlation is performed for simultaneous values of $\mathrm{H}, \mathrm{u}_{*}$ and $\theta_{*}$ at the above mentioned two heights. This is done separately for each day.

(ii) Turbulent Kinetic energy (TKE) / unit mass is evaluated for the two levels and again the correlation is performed for each day.

(iii) TKE / unit mass for the $3^{\text {rd }}$ level is then correlated with $\mathrm{H}, \mathrm{u}_{*}$ and $\theta_{*}$ respectively of the same level.

(iv) TKE / unit mass for the $5^{\text {th }}$ level is also correlated with $\mathrm{H}, \mathrm{u}_{*}$ and $\theta_{*}$ respectively of the same level.

(v) Obukhov length, L is evaluated for the two levels. Again a correlation is performed between them for each day, taking account of the common unstable periods of each day.

\section{DATA USED}

During all ten days of study, data files are available for each hour, barring some gaps in the data. The number of data files with the timings in IST (within the bracket), for different Julian Days are as follows:

175 - $4(9,12,15,18), 176-7(6,12-15,18,23), 177$ - $23(0,2-23), 178$ - $18(0-3,5,7-8$, 10-12, 14-18, 20-21, 23), 179 - 17 (0-9, 11-12, 14-15, 19, 20, 23), 180 - 7 (1, 6, 8-10, 21-22). 198 - $12(6,9,12,14-21,23), 199$ - 12 (11-20, 22-23), 200 - $13(0,6-8,10,12-17,20,22), 201-$ $15(0,2,4,6-10,14-17,19,21,23)$.

It should be noted that the fast sensors supply $8 / 9$ data per second. Each data file is of 10 minute duration. Thus the amount of data in a file varies within the range 4800 - 5400. For a particular hour's data, the arithmetic average taken over the total data set is considered as the mean of the data set, whereas any deviation of a data point from the mean of that particular hour's data set is taken as the fluctuation of that data point. Two time series plots of Sonic wind speed and temperature data are presented as representative curves for a typical Julian day 
177 at 1500 hours IST (Fig. 2). Humidity should be included in the study but due to the continental desert location of Jodhpur, humidity has been neglected. Also, a previous work (Das et al. 2004) shows that the humidity at Jodhpur provides no important information.
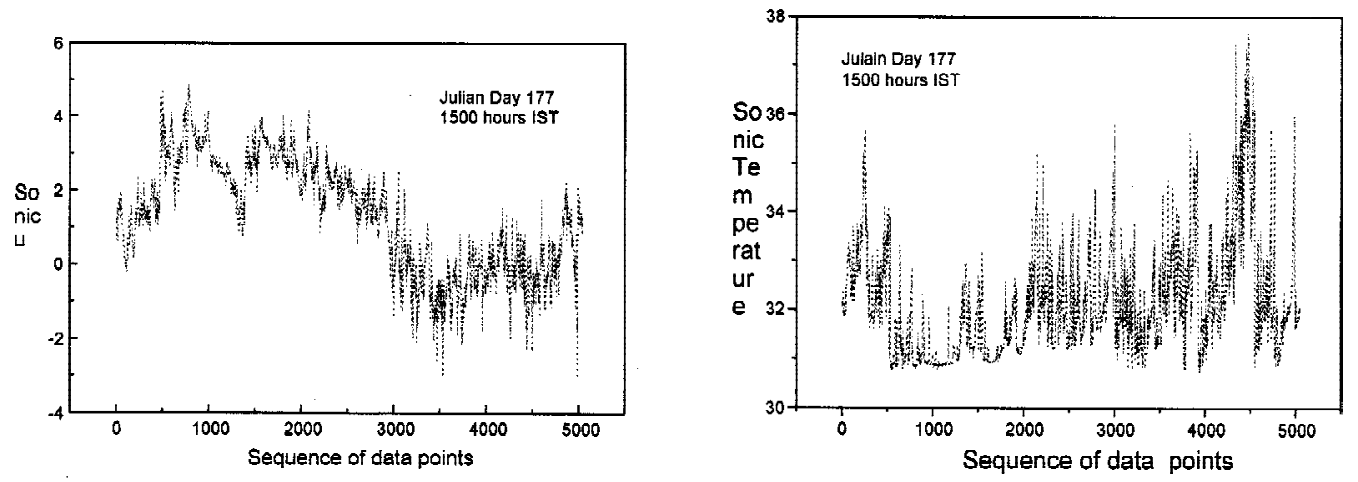

Fig. 2. Time series plot of Sonic wind speed and temperature data.

\section{METHODOLOGY AND PROCEDURES}

In the present study the data collected by fast response sensors are utilized. The data set is purified by removing the abnormal spikes. Then the filtered data are used for further calculations, described in the following subsections.

\subsection{Calculation of Surface Fluxes by the Eddy Correlation Method}

As the fluxes are generated almost entirely due to turbulent mixing, so it is possible to define the fluxes directly in terms of the turbulent (or eddy) component of velocities and of the properties being transferred.

Let us start with the definition of velocity components $\mathrm{u}, \mathrm{v}, \mathrm{w}$ along right handed coordinate axes system $\mathrm{x}, \mathrm{y}$ and $\mathrm{z}$ respectively. These velocity and other scalars can be denoted as

$$
\begin{aligned}
& \mathrm{u}=\overline{\mathrm{u}}+\mathrm{u}^{\prime}, \\
& \mathrm{v}=\overline{\mathrm{v}}+\mathrm{v}^{\prime}, \\
& \mathrm{w}=\overline{\mathrm{w}}+\mathrm{w}^{\prime}, \\
& \theta=\bar{\theta}+\theta^{\prime}, \\
& \mathrm{q}=\overline{\mathrm{q}}+\mathrm{q}^{\prime},
\end{aligned}
$$


Where "over bar" indicates the mean value of the variable and the "prime" is the deviation from the mean value, i.e., the fluctuating component of that variable. $\theta$ and q denote the potential temperature and specific humidity respectively. Over a flat, level, homogeneous surface, $\mathrm{x}$ and $\mathrm{y}$ are taken as horizontal, whereas $\mathrm{z}$ is vertical and positive upwards. The fluxes can now be written as,

$$
\begin{aligned}
& \mathrm{H}=\rho \mathrm{c}_{\mathrm{P}} \overline{\mathrm{w}}^{\prime} \bar{\theta}^{\prime}, \\
& \mathrm{M}=-\rho \overline{\mathrm{w}}^{\prime} \overline{\mathrm{u}}^{\prime}, \\
& \mathrm{E}=\rho \overline{\mathrm{w}}^{\prime} \overline{\mathrm{q}}^{\prime} .
\end{aligned}
$$

Where, H, M, E represents the fluxes of sensible heat, momentum and moisture respectively. $\rho$ denotes the density and $\mathrm{c}_{\mathrm{P}}$ denotes the specific heat at constant pressure.

This method is very reliable for the estimation of surface fluxes, as it is related directly with the turbulence. The only disadvantage is that, this method needs costly fast response sensors that can faithfully follow the fluctuations of all the variables. In the present study, following equation (6), sensible heat flux for the specific period is calculated using data from fast response sensors. The estimation is done for both Sonic sensor collected data at $4 \mathrm{~m}$ and Gill sensor collected data at $15 \mathrm{~m}$ separately. Theoretically, the surface layer is a constant flux layer, but in reality, this was not experienced at Jodhpur. It is assumed that the flux calculated by the eddy correlation method at a particular height, is the flux of the constant flux surface layer upto that height.

\subsection{Intercomparison of Various Surface Parameters From Fast Response Sensors Placed at 4-m and 15-m Levels}

The other important surface layer parameters are calculated using the following formulae:

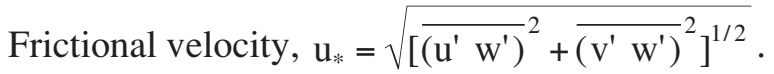

Frictional temperature, $\theta_{*}=-\left(\overline{\mathrm{w}^{\prime} \theta^{\prime}}\right) / \mathrm{u}_{*}$.

Sensible heat flux, $\mathrm{H}=\rho \overline{\mathrm{C}_{\mathrm{P}} \mathrm{w}^{\prime}} \theta^{\prime}$.

Turbulent kinetic energy per unit mass, $\varepsilon=0.5\left(\mathrm{u}^{\prime 2}+\mathrm{v}^{\prime 2}+\mathrm{w}^{\prime 2}\right)$.

Obukhov length, $\mathrm{L}=-\left(\bar{\theta} \mathrm{u}_{*}{ }^{2}\right) / \mathrm{kg} \theta_{*}$. 
Then, all the above-mentioned SBL parameters are estimated using fast response data supplied by Sonic and Gill sensors. The correlation is performed between the parameters derived with the help of data from Sonic and Gill sensors. The theory inherent to the calculation of correlation coefficients is described briefly in the following.

Let $\mathrm{A}$ be a variable and it may be split into mean and turbulent components.

$$
\text { So, } \mathrm{A}=\mathrm{A}+\mathrm{a} \text {, }
$$

Variance of the variable A is measured by the dispersion of data about the mean, which can be written as follows,

$$
\sigma_{A}^{2}=\frac{1}{N} \sum^{\mathrm{N}-1}\left(\mathrm{~A}_{\mathrm{i}}-\overline{\mathrm{A}}\right)^{2},
$$

where $\mathrm{N}$ is the number of observations. In the present case, $\mathrm{N}$ is nothing but the total number of data points, i.e., 4800 to 5400 depending on the frequency of data collection of the sensor. The turbulent or the perturbation or the gust part of a turbulent variable is given by, $\mathrm{a}^{\prime}=\mathrm{A}-\overline{\mathrm{A}}$.

Substituting a' in equation (15), variance is modified as,

$$
\sigma_{A}{ }^{2}=\frac{1}{N} \sum^{N-1} \mathrm{a}_{\mathrm{i}}^{\prime 2}=\overline{\mathrm{a}}_{\mathrm{i}}{ }^{2} .
$$

Since, the standard deviation is the square root of the variance, so the equation is:

$$
\sigma_{A}=\left({\overline{a_{i}}}^{2}\right)^{1 / 2} .
$$

The standard deviation has always the same dimension as the original variable.

Now, according to the theory developed in the standard literature (Stull 1994), the normalized or linear correlation coefficient, $\mathrm{r}_{\mathrm{AB}}$ is defined as:

$$
r_{A B}=\frac{\overline{a_{i}} \overline{b_{i}^{\prime}}}{\overline{\sigma_{A}} .} .
$$

By definition, this variable $r_{A B}$ ranges between -1 and +1 . Two variables that are perfectly correlated (i.e., vary together), yield $\mathrm{r}_{\mathrm{AB}}=1$. Two variables, which are perfectly negatively correlated (i.e., vary oppositely), yield $\mathrm{r}_{\mathrm{AB}}=-1$. Variables with no net variation together, yield poor fractional values of $r$ suffix AB (Stull 1994).

Here, the objective is to estimate the $\mathrm{r}_{\mathrm{AB}}$ in order to study, whether there is any phase relationship between two separate parameters. 


\section{WEATHER CONDITIONS DURING THE STUDY PERIOD}

The present work extends from Julian day 175 to 180, i.e., from June 24 to June 29 during the pre-monsoon period. In the monsoon period, it is from Julian day 198 to 201, i.e., July 17 to July 20. In this section not an exhaustive weather summary, but the special features that occurred during the period of the study, are being discussed. The relevant weather data are collected from the data bank established at the Indian Institute of Tropical Meteorology (IITM), Pune. The main features of the weather system are presented in Table 1, whereas the subsidiary components are supplied in detail in Table $2 \mathrm{~A}$. Table 1 shows that slight rainfall occurred for three days during the complete period of ten days. But the most important feature is that, two days (Julian day 178 and 179) are synoptically significant. A thunderstorm with traces of rainfall was reported on those two days. Simultaneously the temperature (i.e., both maximum and minimum) rose sharply and wind blew with high speed. So it is necessary to observe those two days specifically and attention should be given on different SBL parameters during those two synoptically significant days. Another notable feature, the relative humidity magnitude enhanced largely during the monsoon period compared to the premonsoon period. This information is consistent with our normal expectations.

Table 1. Broad weather information during the period of study.

\begin{tabular}{|c|c|c|c|c|c|c|c|}
\hline & $\begin{array}{l}\text { Julian } \\
\text { Day }\end{array}$ & Date & Humidity & $\begin{array}{l}\text { Maximum } \\
\text { temperature }\end{array}$ & $\begin{array}{l}\text { Minimum } \\
\text { temperature }\end{array}$ & Rainfall & System present \\
\hline \multirow{6}{*}{$\begin{array}{l}\text { During } \\
\text { pre- } \\
\text { monsoon } \\
\text { period }\end{array}$} & 175 & $24^{\text {th }}$ June & $41 \%-62 \%$ & $37.6^{\circ} \mathrm{C}$ & $27.8^{\circ} \mathrm{C}$ & Nil & Nil \\
\hline & 176 & $25^{\text {th }}$ June & $34 \%-58 \%$ & $37.2^{\circ} \mathrm{C}$ & $28.4^{\circ} \mathrm{C}$ & Nil & Nil \\
\hline & 177 & $26^{\text {th }}$ June & $39 \%-72 \%$ & $37.6^{\circ} \mathrm{C}$ & $28.8^{\circ} \mathrm{C}$ & Nil & Nil \\
\hline & 178 & $27^{\text {th }}$ June & $39 \%-60 \%$ & $39.8^{\circ} \mathrm{C}$ & $29.6^{\circ} \mathrm{C}$ & $\begin{array}{c}\text { Trace of } \\
\text { rain }\end{array}$ & $\begin{array}{c}\text { Rain with } \\
\text { thunderstorm } \\
\text { and dust storm }\end{array}$ \\
\hline & 179 & $28^{\text {th }}$ June & $61 \%-62 \%$ & $41.7^{\circ} \mathrm{C}$ & $30.0^{\circ} \mathrm{C}$ & $\begin{array}{l}\text { Trace of } \\
\text { rain }\end{array}$ & $\begin{array}{c}\text { Rain with } \\
\text { thunderstorm }\end{array}$ \\
\hline & 180 & $29^{\text {th }}$ June & $44 \%-63 \%$ & $41.6^{\circ} \mathrm{C}$ & $30.0^{\circ} \mathrm{C}$ & Nil & Nil \\
\hline \multirow{4}{*}{$\begin{array}{c}\text { During } \\
\text { monsoon } \\
\text { period }\end{array}$} & 198 & $17^{\text {th }}$ July & $43 \%-76 \%$ & $36.4^{\circ} \mathrm{C}$ & $28.8^{\circ} \mathrm{C}$ & $0.1 \mathrm{~mm}$ & Rain \\
\hline & 199 & $18^{\text {th }}$ July & $38 \%-68 \%$ & $35.4^{\circ} \mathrm{C}$ & $28.8^{\circ} \mathrm{C}$ & Nil & Nil \\
\hline & 200 & $19^{\text {th }}$ July & $48 \%-69 \%$ & $34.6^{\circ} \mathrm{C}$ & $28.8^{\circ} \mathrm{C}$ & Nil & Nil \\
\hline & 201 & $20^{\text {th }}$ July & $45 \%-71 \%$ & $34.4^{\circ} \mathrm{C}$ & $28.4^{\circ} \mathrm{C}$ & Nil & Nil \\
\hline
\end{tabular}


Table 2A. Detailed weather information during the period of study.

\begin{tabular}{|c|c|c|c|c|c|c|c|c|c|c|c|}
\hline & Julian & \multicolumn{5}{|c|}{ At 0830 hours IST } & \multicolumn{5}{|c|}{ At 1730 hours IST } \\
\hline & & $\begin{array}{l}\text { Cloud } \\
\text { type }\end{array}$ & $\begin{array}{c}\text { Cloud } \\
\text { amount } \\
\text { (octa) }\end{array}$ & $\begin{array}{l}\text { Wind } \\
\text { speed } \\
\text { (Km/ } \\
\text { hour) }\end{array}$ & $\begin{array}{l}\text { Wind } \\
\text { direc- } \\
\text { tion }\end{array}$ & $\begin{array}{c}\text { Station } \\
\text { level } \\
\text { pressure } \\
\text { (hpa) }\end{array}$ & $\begin{array}{l}\text { Cloud } \\
\text { type }\end{array}$ & $\begin{array}{l}\text { Cloud } \\
\text { amount } \\
\text { (octa) }\end{array}$ & $\begin{array}{l}\text { Wind } \\
\text { speed } \\
\text { (Km/ } \\
\text { hour) }\end{array}$ & $\begin{array}{l}\text { Wind } \\
\text { direc- } \\
\text { tion }\end{array}$ & $\begin{array}{c}\text { Station } \\
\text { level } \\
\text { pressure } \\
\text { (hpa) }\end{array}$ \\
\hline \multirow{6}{*}{$\begin{array}{l}\text { During } \\
\text { pre- } \\
\text { Monsoon } \\
\text { period }\end{array}$} & 175 & St & 7 & 22 & WSW & 974.2 & Sc & 6 & 22 & SW & 970.1 \\
\hline & 176 & St & 3 & 6 & SW & 974.6 & $\mathrm{Sc}$ & 4 & 22 & $\overline{\text { WSW }}$ & 971.0 \\
\hline & 177 & Nil & 0 & 15 & WSW & 974.6 & $\mathrm{Sc}$ & 2 & 15 & SW & 970.4 \\
\hline & 178 & Nil & 0 & 12 & SW & 973.3 & $\mathrm{Sc}$ & 1 & 17 & SW & 969.3 \\
\hline & 179 & Nil & 0 & 18 & SW & 974.6 & No & No & 33 & $\mathrm{SE}$ & 970.9 \\
\hline & 180 & Nil & 0 & 15 & WSW & 972.5 & $\mathrm{Sc}$ & 1 & 15 & SW & 969.3 \\
\hline \multirow{4}{*}{$\begin{array}{c}\text { During } \\
\text { monsoon } \\
\text { period }\end{array}$} & 198 & $\mathrm{Sc}$ & 4 & 6 & SW & 974.4 & $\mathrm{Sc}$ & 4 & 6 & W & 970.3 \\
\hline & 199 & $\mathrm{Sc}$ & 3 & 12 & SW & 973.7 & Nil & $\overline{0}$ & 12 & SW & 970.3 \\
\hline & 200 & $\mathrm{Cu}, \mathrm{Sc}$ & 5 & 12 & SW & 974.5 & Sc & 5 & 6 & SW & 970.7 \\
\hline & 201 & $\mathrm{Sc}$ & 6 & 8 & SW & 974.3 & $\mathrm{Sc}$ & 6 & 10 & SSW & 971.4 \\
\hline
\end{tabular}

St- Stratus, Sc- Stratocumulus, Cu- Cumulus.

\section{RESULTS AND DISCUSSIONS}

\subsection{Comparison of Sensible Heat Fluxes Derived from Fast Response Sensors Placed at 4-m and 15-m Levels}

At first, the sensible heat fluxes are calculated by the eddy correlation method (in watt $\mathrm{m}^{-2}$ ) for the above mentioned two different heights. These are presented in Fig. 3. Both sensors show a similar type of diurnal variational pattern of sensible heat flux. But from the Fig. 3, it comes out that, in general, the Sonic sensor placed at $4 \mathrm{~m}$ provides a higher magnitude of sensible heat flux. This observation is very prominent for the Julian days 178 and 179. In this connection, the sunrise, local noon and sunset for the two periods are presented in the Table 2B. At the same time, it is known from the weather information that a thunderstorm with traces of rain was reported to have occurred at night on both days. Though it is known that the magnitude of sensible heat flux decreases linearly with height, such a decrease ought not be as remarkable as that presented. So one can infer, this sharp difference is related to response characteristics of the sensors. Spectral analysis as well as a co-spectra study were then performed on the data from both the sensors. One curve of the u component of wind speed and temperature is presented for each of the two sensors for a typical day. See Fig. 4A. Co-spectra of the vertical component of velocity and temperature from Sonic and Gill data are also presented (Fig. 4B). One can note that the peak in spectral amplitude for Sonic $\mathrm{u}$ and Gill $\mathrm{u}$, and for Sonic temperature and the temperature at Gill height have almost the same respective magnitude. But the peak always occurs at higher frequency for Sonic data. Both the spectra as well as co-spectra of the two sensors are almost identical in all other respects. So from the spectra and co-spectra analysis, no additional difference can be pointed out. Considering all 

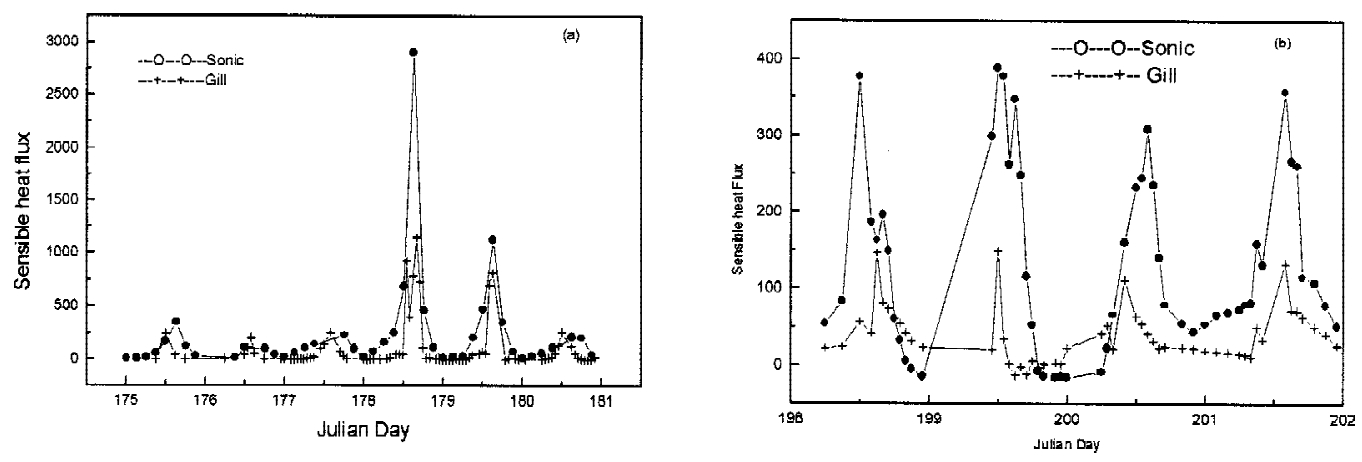

Fig. 3. Comparison of the variation of sensible heat flux derived from Sonic and Gill data using the eddy correlation method (a) for pre-monsoon phase and (b) for monsoon phase.

Table 2B. Sunrise and sunset time for Jodhpur region during pre-monsoon and monsoon phase.

\begin{tabular}{|c|c|c|c|c|}
\hline & $\begin{array}{c}\text { Julian } \\
\text { Day }\end{array}$ & $\begin{array}{c}\text { Sunrise time } \\
\text { (Local Mean Time) }\end{array}$ & $\begin{array}{c}\text { Sunset time } \\
\text { (Local Mean Time) }\end{array}$ & $\begin{array}{c}\text { Local Noon } \\
\text { (Local Mean Time) }\end{array}$ \\
\hline \multirow{4}{*}{$\begin{array}{c}\text { Premonsoon } \\
\text { Phase }\end{array}$} & 175 & $05: 08 \mathrm{AM}$ & $07: 05 \mathrm{PM}$ & $11: 22 \mathrm{AM}$ \\
\cline { 2 - 5 } & 176 & $05: 08 \mathrm{AM}$ & $07: 06 \mathrm{PM}$ & $11: 22 \mathrm{AM}$ \\
\cline { 2 - 5 } & 177 & $05: 08 \mathrm{AM}$ & $07: 06 \mathrm{PM}$ & $11: 22 \mathrm{AM}$ \\
\cline { 2 - 5 } & 178 & $05: 08 \mathrm{AM}$ & $07: 06 \mathrm{PM}$ & $11: 22 \mathrm{AM}$ \\
\cline { 2 - 5 } & 179 & $05: 09 \mathrm{AM}$ & $07: 06 \mathrm{PM}$ & $11: 22 \mathrm{AM}$ \\
\hline \multirow{3}{*}{\begin{tabular}{c} 
Monsoon \\
\cline { 2 - 5 }
\end{tabular}} & 180 & $05: 09 \mathrm{AM}$ & $07: 06 \mathrm{PM}$ & $11: 22 \mathrm{AM}$ \\
\cline { 2 - 5 } & 198 & $05: 17 \mathrm{AM}$ & $07: 03 \mathrm{PM}$ & $11: 22 \mathrm{AM}$ \\
\cline { 2 - 5 } & 199 & $05: 18 \mathrm{AM}$ & $07: 03 \mathrm{PM}$ & $11: 22 \mathrm{AM}$ \\
\cline { 2 - 5 } & 200 & $05: 18 \mathrm{AM}$ & $07: 02 \mathrm{PM}$ & $11: 22 \mathrm{AM}$ \\
\cline { 2 - 5 } & 201 & $05: 19 \mathrm{AM}$ & $07: 02 \mathrm{PM}$ & $11: 22 \mathrm{AM}$ \\
\hline
\end{tabular}

the above-mentioned facts together, one can infer that the Sonic sensor is more sensitive than the Gill sensor. This is better reflected, when convective development occurs. Further, a large peak in the surface heat flux value is recorded for both the sensors on Julian day 178 and 179. Incidentally, a thunderstorm also occurred on those two days. So it can be suggested that the existence of large sensible heat flux points to the occurrence of convective development within the next few hours.

\subsection{Intercomparison of Various Surface Layer Parameters Derived from Fast Response Sensors Placed at 4-m and 15-m Levels}

$\mathrm{u}_{*}$, and $\theta_{*}$ for the two levels for each of the 10 days of the study have been estimated separately. Each parameter calculated for both heights are plotted separately for daytime and nighttime. Some representative graphs are given here to make the work comprehensive (Fig. 5). 

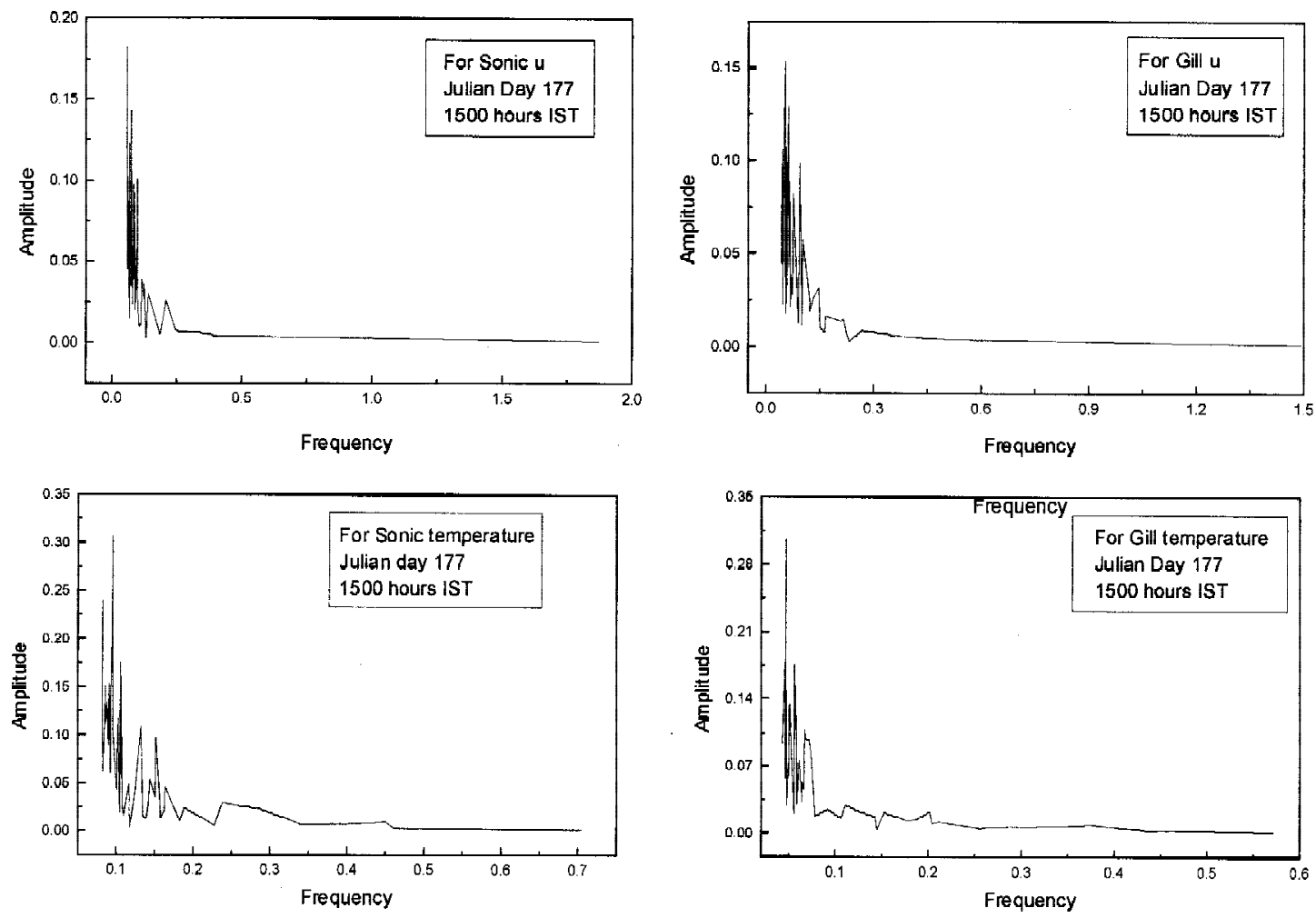

Fig. 4A. Spectral analysis of $\mathrm{u}$ component of wind speed and temperature data for both Sonic and Gill Sensor.
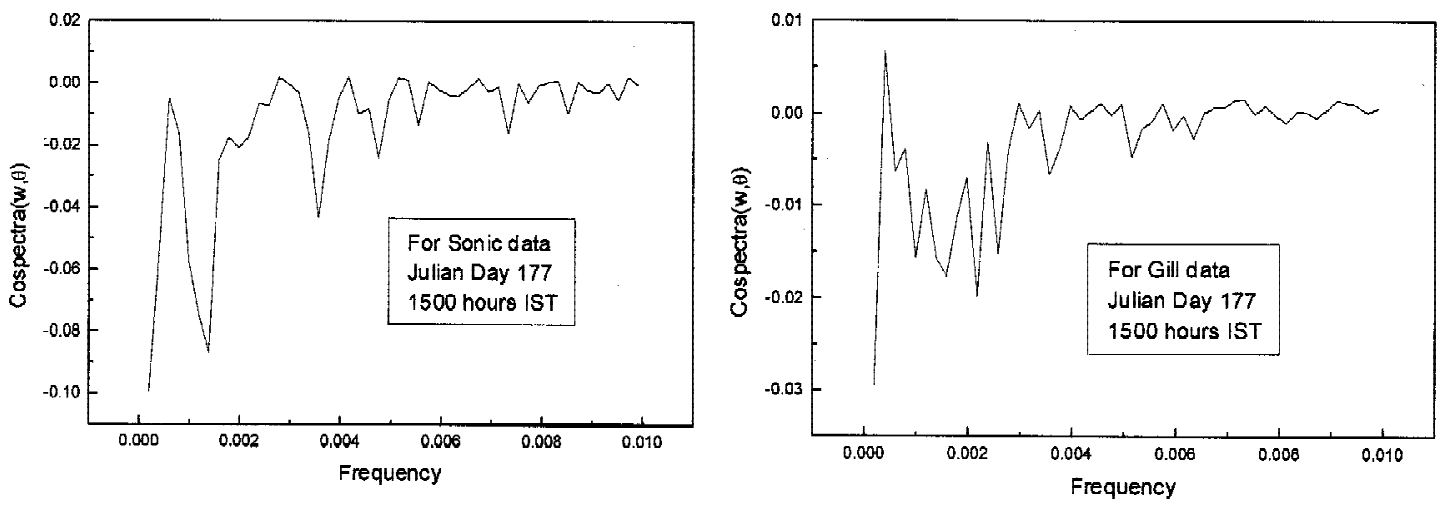

Fig. 4B. Co-spectra of w component of wind speed and temperature data for both Sonic and Gill Sensor. 
Then the correlation between the parameters for two different heights has been estimated and presented in Table 3A. Table 3B is presented after separating the daytime and night-time data for the total period of study. It turns out that the overall correlation for heat flux derived from the two sensors is good. This is significantly good on days 178 and 179 (June 27 and 28), when heat flux rises sharply to high values around 1400 hours IST on day 178 and 1500 hours IST on day 179. The correlation is poor on three occasions, i.e., on day 180, 199 and 200. Incidentally there was thunderstorm rain at midnight of day 179 - 180 and the monsoon was active on days 199 and 200. This shows that when monsoon is active or when convection sharply decreases in pre-monsoon periods (as happened on day 180, when maximum heat flux recorded by the Sonic sensor is only 58.05 watt $\mathrm{m}^{-2}$ at about 1500 hours IST), the correlation becomes
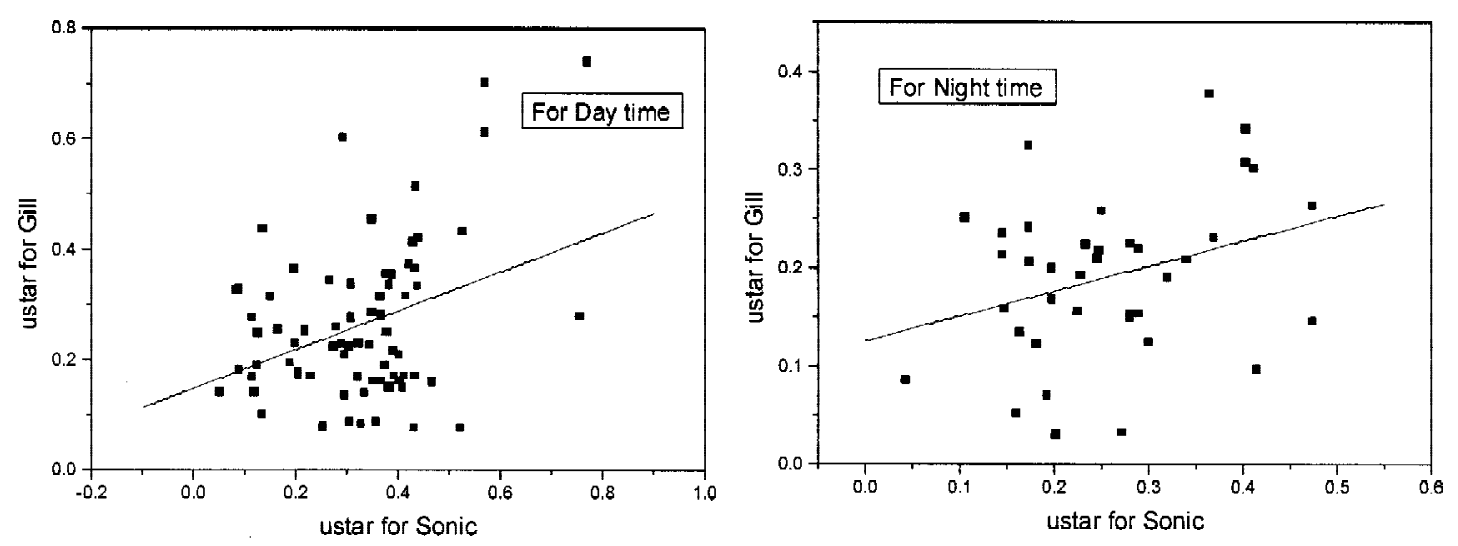

Fig. 5. Scatter plot of different parameters measured at $3^{\text {rd }}$ and $5^{\text {th }}$ level.

Table 3A. Correlation of different parameters measured at $3^{\text {rd }}$ and $5^{\text {th }}$ level.

\begin{tabular}{|cccc|}
\hline \multicolumn{4}{|c|}{ Correlation } \\
\hline $\begin{array}{c}\text { Julian } \\
\text { Day }\end{array}$ & $\mathrm{U}_{*}$ & $\theta_{*}$ & $\mathrm{H}$ \\
\hline 175 & -0.268 & 0.603 & 0.602 \\
\hline 176 & 0.590 & 0.670 & 0.628 \\
\hline 177 & -0.432 & 0.509 & 0.599 \\
\hline 178 & 0.787 & 0.609 & 0.908 \\
\hline 179 & 0.861 & 0.791 & 0.885 \\
\hline 180 & 0.039 & 0.495 & 0.207 \\
\hline 198 & 0.465 & 0.836 & 0.825 \\
\hline 199 & 0.469 & 0.348 & 0.424 \\
\hline 200 & 0.309 & -0.472 & 0.381 \\
\hline 201 & 0.810 & 0.603 & 0.740 \\
\hline
\end{tabular}


Table 3B. Correlation of different parameters measured at $3^{\text {rd }}$ and $5^{\text {th }}$ level, separating for day and night time.

\begin{tabular}{|c|c|c|}
\hline Heat Elux & Day & $8.230875 \mathrm{E}-001$ \\
\cline { 2 - 3 } & Night & $4.177712 \mathrm{E}-002$ \\
\hline \multirow{3}{*}{$u_{*}$} & Day & $3.518559 \mathrm{E}-001$ \\
\cline { 2 - 3 } & Night & $3.090472 \mathrm{E}-001$ \\
\hline \multirow{2}{*}{$\theta_{*}$} & Day & $3.626639 \mathrm{E}-001$ \\
\cline { 2 - 3 } & Night & $-4.007035 \mathrm{E}-001$ \\
\hline \multirow{2}{*}{ TKE } & Day & $8.755320 \mathrm{E}-001$ \\
\cline { 2 - 3 } & Night & $8.368305 \mathrm{E}-001$ \\
\hline
\end{tabular}

highly non-uniform vertically, even within the surface layer height.

$\mathrm{u}_{*}$ correlation is significantly good on days 178,179 and 201. $\theta_{*}$ correlation is below 0.5 only on three days, i.e., 180, 199 and 200, out of ten days. Incidentally, on all three days the humidity is high. In fact, the correlation for all the three parameters is good on days 178 and 179. This evidently means that turbulence behavior is quite uniform over the vertical height (at least upto $15 \mathrm{~m}$ ) on those two days. Then the flux Richardson number Ri (Stull 1994), and convective velocity $\mathrm{W}_{*}$ (Stull 1994) for the total period of study was estimated (Table 4). This is done to distinguish the days of deep convection during the period. The results show that on two specific days, 178 and $179, \mathrm{w}_{*}$ rose significantly and also a high magnitude of $\mathrm{R}_{\mathrm{i}}$ was observed. So, one can conclude that deep convection occurs on those two days, which is supported by the unusual rise of estimated sensible heat flux.

In the next, TKE / unit mass is derived from the fast response data set (i.e., for both Sonic and Gill separately). First of all, the TKE derived at the two heights are plotted simultaneously to observe their relationship (Fig. 6). Separate graphs are plotted for daytime and nighttime data. Figure 5 shows that TKE at both the heights are well correlated. Then TKE / unit mass derived from the response of two sensors at two different heights is correlated and the result of correlation is presented in Table 5. Previously, in Table 3B, correlation of TKE / mass is given separating the daytime and nighttime data for the total period of study. The correlation for TKE/unit mass is very good on all ten days of the study period. Diurnal variation of TKE / unit mass given by Sonic and Gill are presented in Fig. 7. It is quite significant that TKE-s given by both the sensors are almost same on the days 178, 179 and 180. Otherwise TKE derived from the Sonic sensor is more than that derived from the Gill sensor. However, the results reveal that, in general, TKE at the 4-m level is larger in magnitude than the TKE at the 15-m level. So it appears that turbulence at the $3^{\text {rd }}$ level is more vigorous than that at the $5^{\text {th }}$ level. This is quite relevant as the $3^{\text {rd }}$ level is nearer to the earth's surface compared to the $5^{\text {th }}$. Again, during monsoon phase, the difference is very sharp. So it can be said that, TKE at $4 \mathrm{~m}$ high varies largely compared to the TKE at $15 \mathrm{~m}$ high during the monsoon phase. So the turbulence is expected to be non-uniform over the vertical height during the monsoon phase. Again, the magnitude of TKE is much less at the monsoon phase, which supports the fact that turbulence intensity decreases at the monsoon phase compared to that of pre-monsoon phase, i.e., a monsoon is a more stable phenomenon than the pre-monsoon phase. 
Table 4. Value of some surface layer parameters during the observation period.

\begin{tabular}{|c|c|c|c|}
\hline Date & $\begin{array}{c}\text { Time } \\
\text { (IST) }\end{array}$ & $\mathrm{R}_{\mathrm{i}}$ & $\mathrm{W}_{*}$ \\
\hline 175 & 0900 & -0.138 & 0.192 \\
& 1200 & -0.355 & 0.337 \\
& 1500 & -0.456 & 0.196 \\
& 1800 & -0.185 & 0.063 \\
\hline 176 & 1200 & -0.174 & 0.219 \\
& 1300 & -1.413 & 0.434 \\
& 1400 & $\ldots \ldots .$. & 0.341 \\
& 1500 & $\ldots \ldots .$. & 0.366 \\
& 1800 & -0.173 & 0.167 \\
\hline 177 & 0800 & -0.179 & 0.101 \\
& 1100 & -2.212 & 0.278 \\
& 1200 & -3.801 & 0.282 \\
& 1400 & -4.200 & 0.162 \\
& 1500 & -3.210 & 0.086 \\
& 1800 & -1.572 & 0.086 \\
& & & \\
\hline 178 & 0800 & -0.554 & 0.128 \\
& 1000 & -1.230 & 0.196 \\
& 1200 & -3.324 & 0.289 \\
& 1500 & -16.172 & 0.494 \\
& 1700 & -2.964 & 0.309 \\
& 1900 & -2.027 & 0.227 \\
\hline 179 & 0800 & -0.264 & 0.163 \\
& 0900 & -0.664 & 0.267 \\
& 1000 & -0.081 & 0.247 \\
& 1200 & -0.581 & 0.111 \\
& 1400 & -0.096 & 0.344 \\
& 1500 & -2.150 & 0.496 \\
& 1900 & -0.038 & 0.163 \\
\hline 180 & 0800 & -0.271 & 0.181 \\
& 0900 & -0.441 & 0.182 \\
& 1000 & -0.923 & 0.121 \\
\hline 198 & 0900 & -0.535 & 0.205 \\
& 1200 & -4.204 & 0.306 \\
& 1400 & -3.764 & 0.267 \\
& 1600 & -2.854 & 0.271 \\
& 1800 & -1.487 & 0.183 \\
\hline 199 & 1000 & -0.707 & 0.313 \\
& 1200 & -1.133 & 0.342 \\
& 1400 & -1.323 & 0.342 \\
& 1500 & -1.239 & 0.328 \\
& 1600 & -1.167 & 0.293 \\
& 1800 & -0.569 & 0.175 \\
\hline 200 & 0800 & -0.452 & 0.189 \\
& 1200 & -0.783 & 0.288 \\
& 1500 & -0.578 & 0.289 \\
& 2000 & -0.324 & $\ldots \ldots$. \\
\hline & 0900 & -0.569 & 0.255 \\
& 1400 & -0.657 & 0.305 \\
& 1600 & -1.347 & 0.299 \\
1900 & -0.472 & 0.120 \\
\hline & & & \\
\hline 101
\end{tabular}



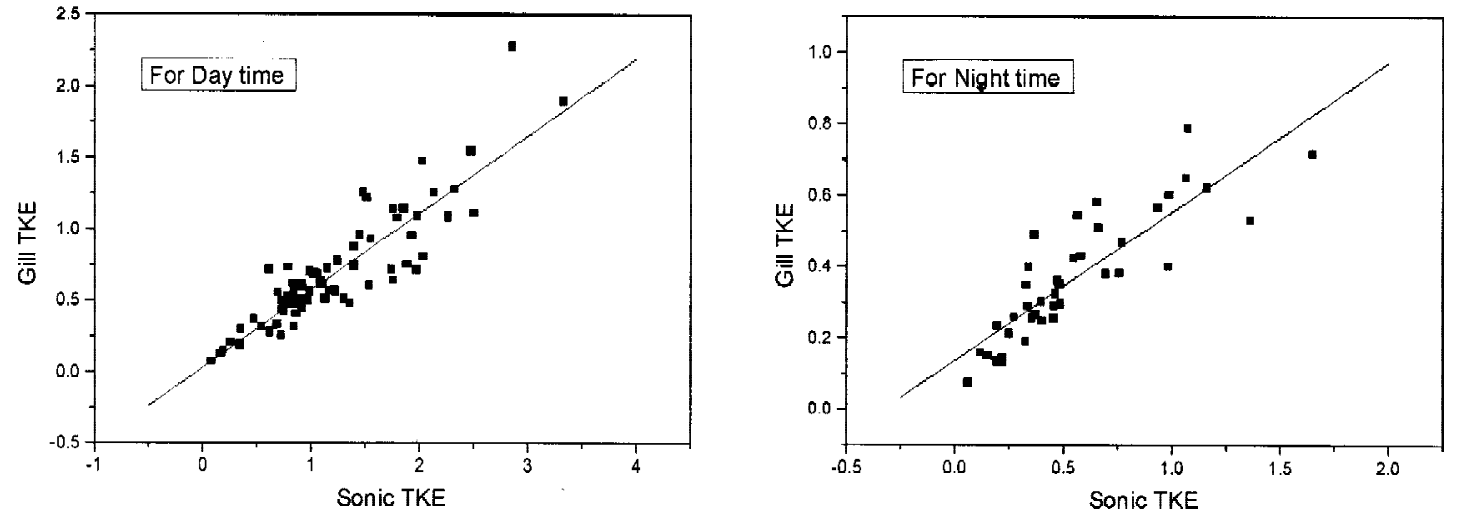

Fig. 6. Scatter plot of TKE / unit mass measured at $3^{\text {rd }}$ and $5^{\text {th }}$ level.

Table 5. Correlation for TKE/unit mass between $3^{\text {rd }}$ and $5^{\text {th }}$ level.

\begin{tabular}{|c|c|}
\hline Julian Day & Correlation \\
\hline 175 & 0.957 \\
\hline 176 & 0.987 \\
\hline 177 & 0.965 \\
\hline 178 & 0.863 \\
\hline 179 & 0.983 \\
\hline 180 & 0.978 \\
\hline 198 & 0.714 \\
\hline 199 & 0.939 \\
\hline 200 & 0.941 \\
\hline 201 & 0.938 \\
\hline
\end{tabular}

Then, at the 4-m level TKE / unit mass was plotted with $\mathrm{H}, \mathrm{u}_{*}$ and $\theta_{*}$ respectively of the same height. Separate graphs are plotted for daytime and nighttime data sets. Some representative graphs are shown (Fig. 8). Then TKE / unit mass was correlated with $\mathrm{H}, \mathrm{u}_{*}$ and $\theta_{*}$ and the outcome is presented in Table $6 \mathrm{~A}$. Also Table $6 \mathrm{~B}$ is presented after separating the daytime and night data for the total period of study. Correlation with $\mathrm{H}$ is above 0.75 on five occasions of which three occasions fall during monsoon time. The other two occasions fall on synoptically significant days of 178 and 179 . Correlation with $\mathrm{u}_{*}$ is in general good during the monsoon period and it is also good on days 178 and 179. It is observed that on all days there is 

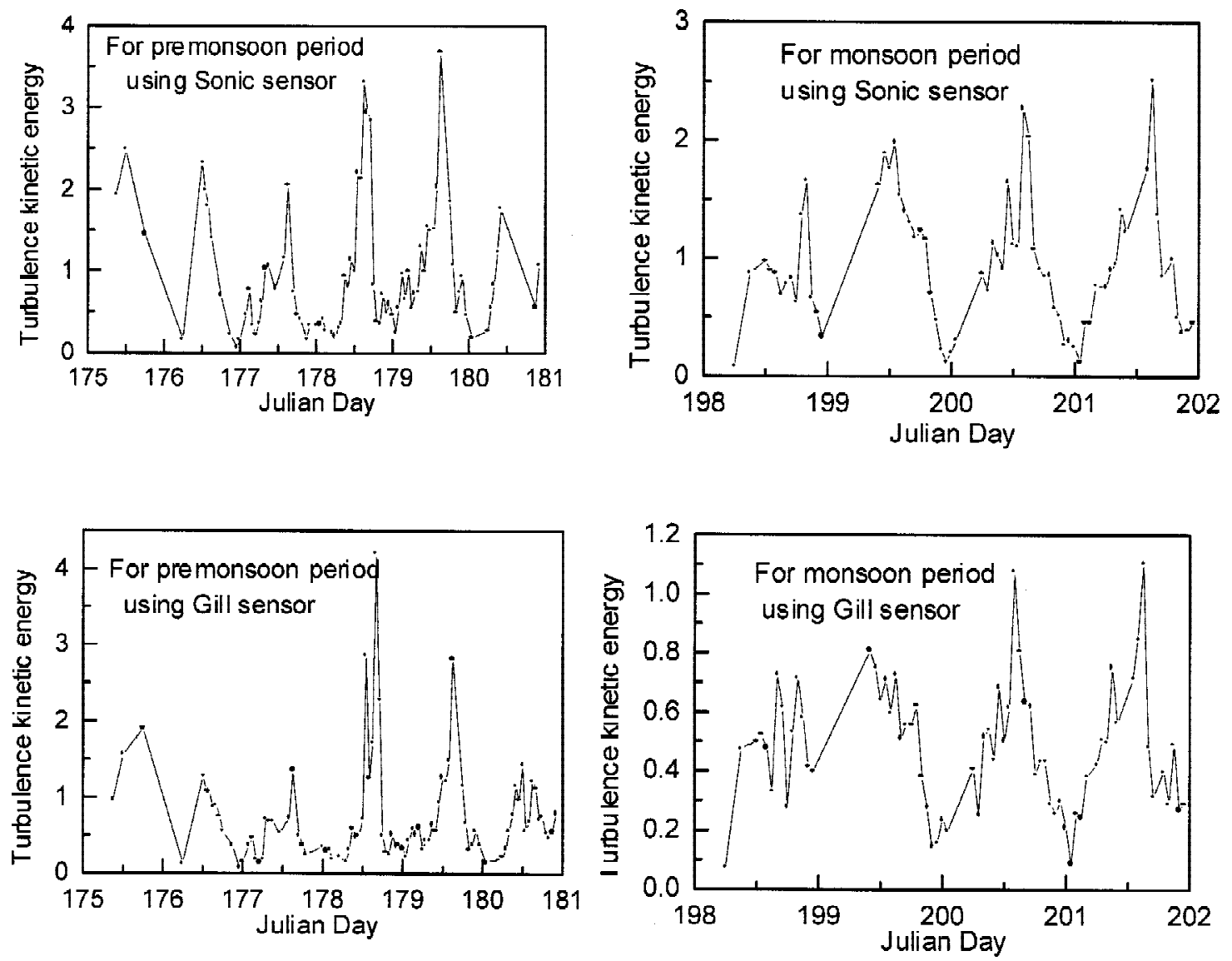

Fig. 7. Variation of TKE/unit mass derived at $3^{\text {rd }}$ and $5^{\text {th }}$ level (a) for pre-monsoon phase and (b) for monsoon phase.

negative correlation between TKE and $\theta_{*}$. This is quite consistent as $\theta_{*}$ is defined as the ratio between heat flux and $\mathrm{u}_{*}$ with a minus sign. So when heat flux which generates TKE is positive, $\theta_{*}$ would be negative. The correlation is good on three out of four days of the monsoon period considered. Again it has been seen that the correlation is quite good on all the days preceded by rain, i.e., on days 179, 180, 199 and 200 .

Similarly, TKE / unit mass at the $15-\mathrm{m}$ level was plotted with $\mathrm{H}, \mathrm{u}_{*}$ and $\theta_{*}$ respectively of the same level for daytime and nighttime (Fig. 9). Then correlation of TKE / unit mass with H, $\mathrm{u}_{*}$ and $\theta_{*}$ was presented in Table 7A. In addition, Table 7B indicates results presented after separating the daytime and nighttime data for the total period of study. The correlation of TKE with $\mathrm{H}$ is quite good during pre-monsoon phase and it is very high on two significant days of 178 and 179. Correlation is, in general, poor during the monsoon phase. Correlation of TKE with $\mathrm{u}_{*}$ is very significant on days 178 and 179 . Otherwise it is, in general, good during the pre-monsoon phase. During the monsoon phase the correlation is poor. This is exactly the 

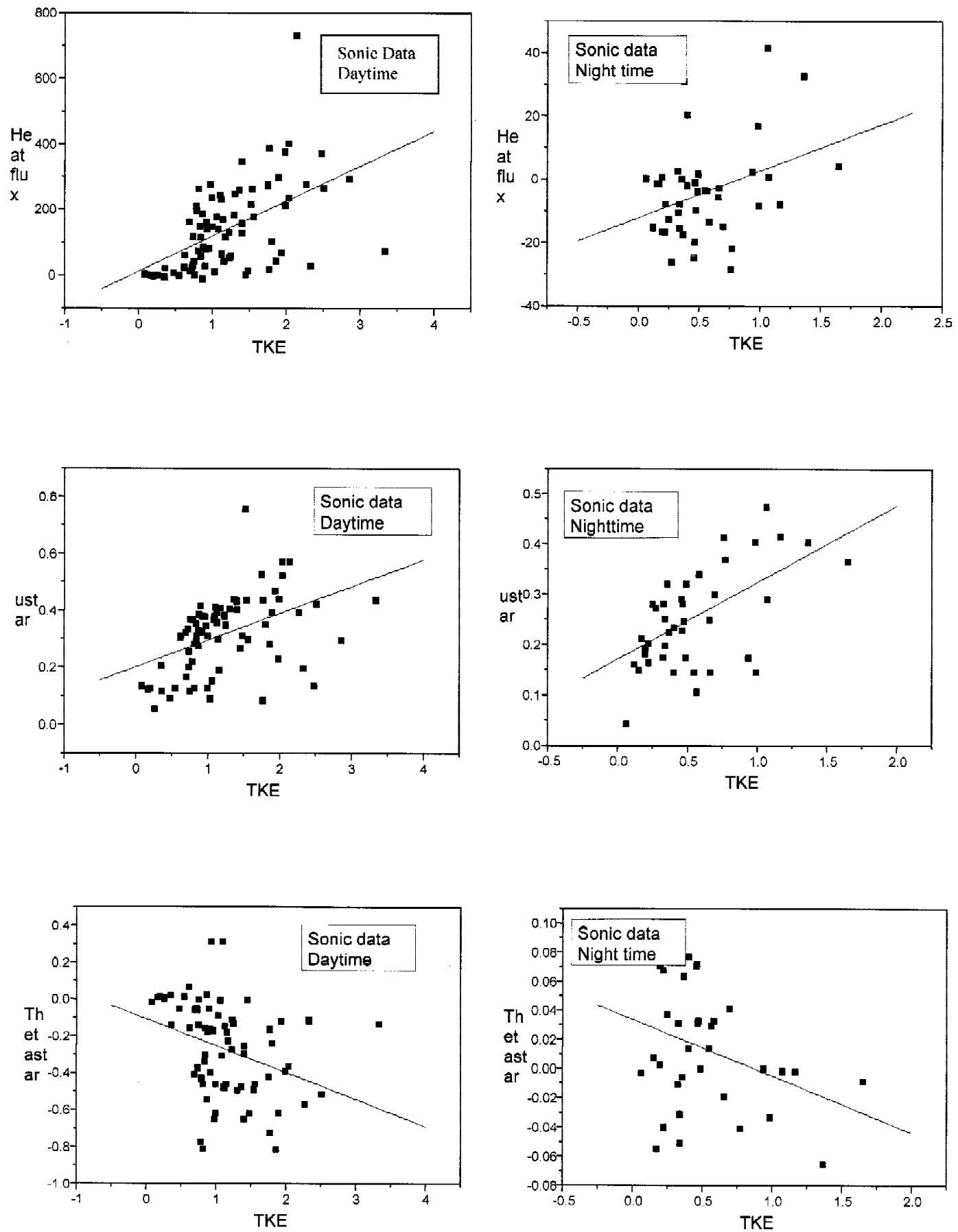

Fig. 8. Scatter plot of TKE / unit mass with different parameters measured at $3^{\text {rd }}$ level 
Table 6A. Correlation between TKE/unit mass for 3rd level and different parameters at the same level.

\begin{tabular}{|c|c|c|c|}
\hline Julian Day & \multicolumn{3}{|c|}{ Correlation } \\
\hline & $\mathrm{H}$ & $\mathrm{u}_{*}$ & $\theta_{*}$ \\
\hline 175 & 0.288 & 0.209 & -0.189 \\
\hline 176 & 0.630 & 0.718 & -0.745 \\
\hline 177 & 0.520 & 0.251 & -0.358 \\
\hline 178 & 0.770 & 0.783 & -0.084 \\
\hline 179 & 0.898 & 0.909 & -0.759 \\
\hline 180 & 0.423 & 0.248 & -0.730 \\
\hline 198 & 0.127 & 0.788 & -0.067 \\
\hline 199 & 0.794 & 0.619 & -0.838 \\
\hline 200 & 0.820 & 0.811 & -0.775 \\
\hline 201 & 0.882 & 0.746 & -0.723 \\
\hline
\end{tabular}

Table 6B. Correlation between TKE/unit mass for $3^{\text {rd }}$ level and different parameters at the same level, separating day and night time.

\begin{tabular}{|c|c|c|}
\hline Heat & Day & $5.130102 \mathrm{E}-001$ \\
\cline { 2 - 3 } Flux & Night & $3.417115 \mathrm{E}-001$ \\
\hline \multirow{3}{*}{$u_{*}$} & Day & $4.466503 \mathrm{E}-001$ \\
\cline { 2 - 3 } & Night & $5.228910 \mathrm{E}-001$ \\
\hline \multirow{2}{*}{$\theta_{*}$} & Day & $-3.304532 \mathrm{E}-001$ \\
\cline { 2 - 3 } & Night & $-3.310714 \mathrm{E}-001$ \\
\hline
\end{tabular}

reverse of the situation at the 4-m level. But consistency lies only for days 178 and 179. Correlation of TKE with $\theta_{*}$ is again in general negatively related. The negative correlation is in general good during the pre-monsoon phase. During two days of monsoon rain, the correlation becomes positive, though the poor value signifies an uncorrelated situation. But the inverse correlation is very good on days 178 and 179.

Then, Obukhov length $\mathrm{L}$ was evaluated at $4 \mathrm{~m}$ as well as $15 \mathrm{~m}$. Correlation was performed for each day for the common unstable period. The results are presented in Table 8. Julian Day 175 is not presented for paucity of data during the chosen period. The correlation is above 0.7 on five out of nine cases. The correlation is poor during the two days of monsoon rain and the first day of sharp temperature rise, i.e., Julian day 178, though the correlation of $\mathbf{u}_{*}$ and $\theta_{*}$ are not bad on that day of 178 . 

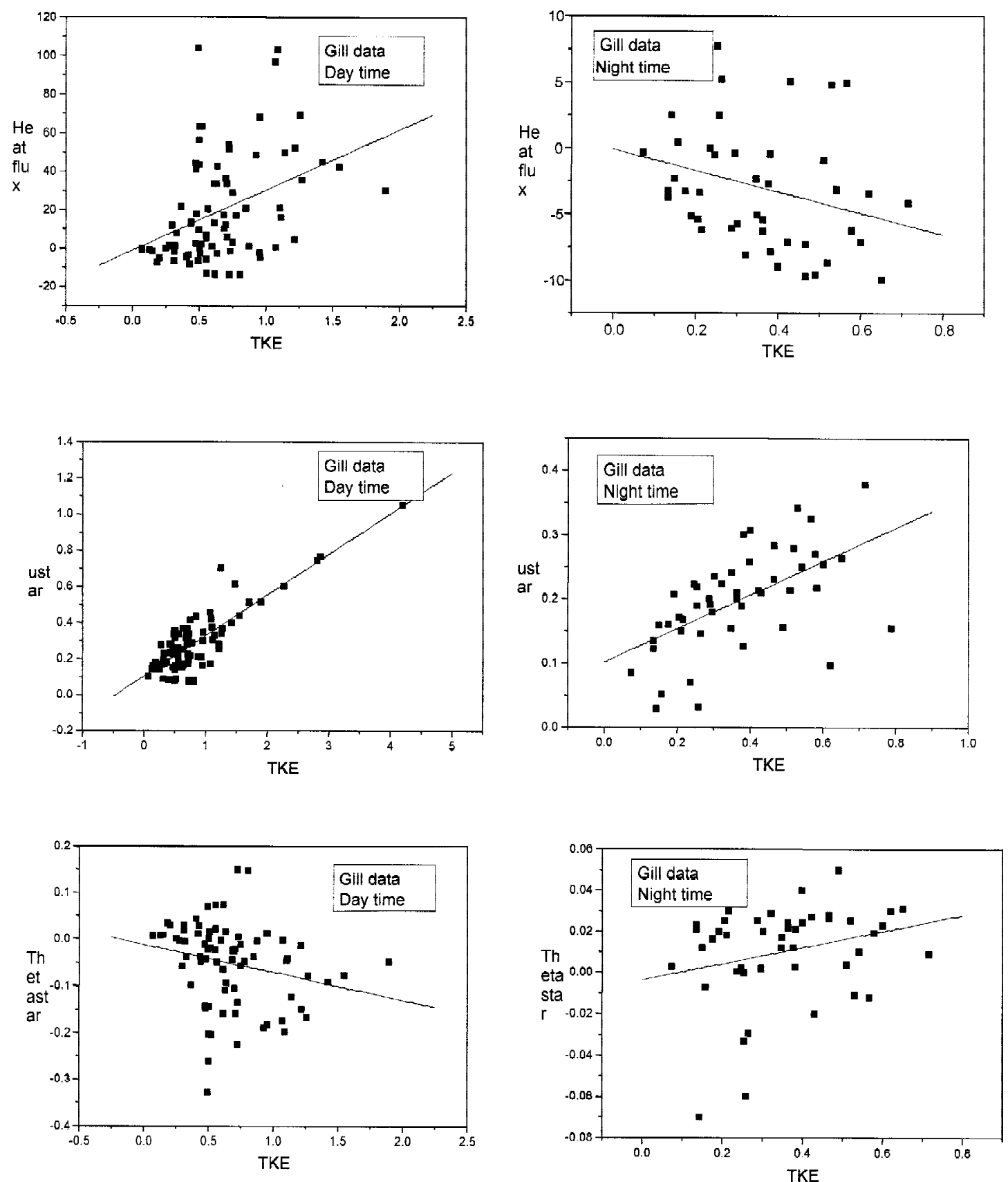

Fig. 9. Scatter plot of TKE / unit mass with different parameters measured at $5^{\text {th }}$ level 
Table 7A. Correlation between TKE/unit mass for $5^{\text {th }}$ level and different parameters at the same level.

\begin{tabular}{|cccc|}
\hline Julian Day & \multicolumn{3}{c|}{ Correlation } \\
\hline & $\mathrm{H}$ & $\mathrm{u} *$ & $\theta_{*}$ \\
\hline 175 & 0.868 & 0.871 & -0.827 \\
\hline 176 & 0.672 & 0.886 & -0.707 \\
\hline 177 & 0.523 & 0.518 & -0.491 \\
\hline 178 & 0.945 & 0.956 & -0.956 \\
\hline 179 & 0.901 & 0.906 & -0.916 \\
\hline 180 & 0.675 & 0.677 & -0.657 \\
\hline 198 & 0.223 & 0.597 & -0.181 \\
\hline 199 & 0.189 & 0.555 & 0.122 \\
\hline 200 & -0.086 & 0.173 & 0.236 \\
\hline 201 & 0.691 & 0.728 & -0.642 \\
\hline
\end{tabular}

Table 7B. Correlation between TKE/unit mass for $5^{\text {th }}$ level and different parameters at the same level, separating day and nighttime.

\begin{tabular}{|c|c|c|}
\hline Heat & Day & $3.827709 \mathrm{E}-001$ \\
\cline { 2 - 3 } Flux & Night & $-2.685073 \mathrm{E}-001$ \\
\hline \multirow{2}{*}{$u_{*}$} & Day & $8.395839 \mathrm{E}-001$ \\
\cline { 2 - 3 } & Night & $5.636169 \mathrm{E}-001$ \\
\hline \multirow{2}{*}{$\theta_{*}$} & Day & $-2.247648 \mathrm{E}-001$ \\
\cline { 2 - 3 } & Night & $2.581114 \mathrm{E}-001$ \\
\hline
\end{tabular}

Table 8. Correlation of Obukov length (L) derived at $3^{\text {rd }}$ and $5^{\text {th }}$ level.

\begin{tabular}{|c|c|}
\hline Julian Day & Correlation \\
\hline 176 & 0.719 \\
\hline 177 & 0.515 \\
\hline 178 & 0.201 \\
\hline 179 & 0.706 \\
\hline 180 & 0.949 \\
\hline 198 & 0.940 \\
\hline 199 & 0.366 \\
\hline 200 & 0.250 \\
\hline 201 & 0.990 \\
\hline
\end{tabular}




\section{CONCLUSIONS}

Sensible heat fluxes calculated at two different heights show identical diurnal variation patterns, though the magnitudes differ largely at the two heights. This helps to suggest that the Sonic sensor is more sensitive than the Gill sensor. This work can be extended, taking large number data sets of different regions. Again, one can conclude from sensible heat flux and also other parameters, that the monsoon period is less convective, i.e. more stable than the premonsoon period.

The correlation between different parameters at the same height and also same parameters at different heights show that the correlation coefficient value is good during convective situations.

The present study points that there are two synoptically significant days within the period of work. At the same time, deep convection occurs on those two days associated with a very high magnitude of sensible heat flux. All the correlations at different heights on those two days provide very good values, which supports that homogeneous turbulence exists up to a vertical height of at least $15 \mathrm{~m}$, when deep convection is present.

Acknowledgement The authors thank the DST, Govt. of India, for the sanctio of a research project. The present work is a part of that project. The authors would also like to thank Indian Institute of Tropical Meteorology, Pune, for the supply of data. The authors are also grateful to the referees for their valuable comments.

\section{REFERENCES}

Das, N., M. Bose, and U. K. De, 2004: Identification of a surface layer structure and analysis of humidity data in two weather situations at Jodhpur $\left(26^{\circ} 18^{\prime} \mathrm{N}, 73^{\circ} 04^{\prime} \mathrm{E}\right)$, India, during MONTBLEX'1990. Proc Indian Acad. Sc., (Earth and Planet. Sci.), 113 73-87.

Goel, M., and H. N. Srivastava, 1989: MONTBLEX. Vayu Mandal, 20, 1-8.

Kailas, S. V., and M. Goel, 1997: Planning MONTBLEX- An overview. In: R. Narasimha et al. (Eds.), The Monsoon Trough Boundary Layer, p33.

Kaimal, J. C., and J. J. Finnigan, 1994: Atmospheric boundary layer flows. Oxford Unive. Press NY, 289pp.

Mohanty, U. C., Parihar P. S., T. Venugopal, and Parashuram, 1997: Estimation of drag coefficient over the western desert sector of the Indian summer monsoon trough. In: R. Narasimha et al. (Eds.), The Monsoon Trough Boundary Layer, p261.

Rajkumar, G., R. Narasimha, S. P. Singal, and B. S. Gera, 1997: Thermal and wind structure of the monsoon trough boundary layer. In: R. Narasimha et al. (Eds.), The Monsoon Trough Boundary Layer, p153.

Rao, K. G., 1997: Roughness length and drag coefficient at two MONTBLEX-90 tower stations. In: R. Narasimha et al. (Eds.), The Monsoon Trough Boundary Layer, p245. 
Rao, K. G., R. Narasimha, and A. Prabhu, 1997: An analysis of MONTBLEX data on heat and momentum flux at Jodhpur. In: R. Narasimha et al. (Eds.), The Monsoon Trough Boundary Layer, p277.

Rao, Narahari K., 1997: Estimation of surface temperature from MONTBLEX data. In: R. Narasimha et al. (Eds.), The Monsoon Trough Boundary Layer, p125.

Roy, B., and U. K. De, 1997: Study of horizontal scales of motion observed over Kharagpur during MONTBLEX-1990. In: R. Narasimha et al. (Eds.), The Monsoon Trough Boundary Layer, p185.

Rudra, K. S., and Prabhu, 1991: Quality assessment of Tower Data from MONTBLEX'90, Workshop on Preliminary Scientific Results of MONTBLEX Research Results, DST. , IISc, Bangalore, 45-68.

Rudra, Kumar S, S. Ameenulla, and A. Prabhu, 1997: MONTBLEX tower observations: Instrumentation, data acquisition and data quality. In: R. Narasimha et al. (Eds.), The Monsoon Trough BoundaryLayer, p97.

Sadani, L. K., and B. S. Murthy, 1997: Estimation of surface heat flux and inversion height with a Doppler acoustic sounder. In: R. Narasimha et al. (Eds.), The Monsoon Trough Boundary Layer, p293.

Sikka, D. R., and R. Narasimha, 1997: Genesis of the monsoon trough boundary layer experiment (MONTBLEX). In: R. Narasimha et al. (Eds.), The Monsoon Trough Boundary Layer, p1.

Srivastav, S. K., 1997: Synoptic meteorological observations and weather conditions during MONTBLEX-90. In: R. Narasimha et al. (Eds.), The Monsoon Trough Boundary Layer, p51.

Stull, R. B., 1994: An Introduction to Boundary Layer Meteorology). Kluwer Academic Dordrecht, $665 \mathrm{pp}$.

Viswanadham, D. V., and A. N. V. Satyanarayana, 1997: Atmospheric surface layer parameters during different phases of monsoon over Varanasi from MONTBLEX-90. In: R. Narasimha et al. (Eds.), The Monsoon Trough Boundary Layer, p313. 